\title{
Impact of Media Aging on the Removal of Cryptosporidium in Granular Media Filters
}

\section{Isabelle Papineau ${ }^{1, *}$, Nathalie Tufenkji ${ }^{2}$, Pierre Servais ${ }^{3}$ and Benoit Barbeau ${ }^{4}$}

${ }^{1}$ Ph.D. Candidate, Industrial NSERC Chair on Drinking Water, Department of Civil, Geological and Mining Engineering, Ecole Polytechnique de Montreal, P.O. Box 6079, Downtown Station, Montreal, Quebec, Canada, H3C 3A7.

E-mail: isabelle.papineau@ polymtl.ca ; Tel.: 1.514.340.4711 x 3711; Fax:

1.514.340.5918.

*Corresponding author

${ }^{2}$ Associate Professor, Department of Chemical Engineering, McGill University, Montreal, Quebec, Canada, H3A 2B2.

E-mail: nathalie.tufenkji@mcgill.ca . Tel.: 1.514.398.2999. Fax: 1.514.398.6878.

${ }^{3}$ Professor, Ecologie des Systemes Aquatiques, Universite Libre de Bruxelles Campus de la Plaine, C.P. 221, Boulevard du Triomphe, Bruxelles 1050, Belgium.

E-mail: pservais@ulb.ac.be. Tel.: 02.650.59.95. Fax: 02.650.59.93.

${ }^{4}$ Associate Professor and Associate Chairholder, Industrial NSERC Chair on Drinking Water, Department of Civil, Geological and Mining Engineering, Ecole Polytechnique de Montreal, P.O. Box 6079, Downtown Station, Montreal, Quebec, Canada, H3C 3A7. E-mail: benoit.barbeau@ polymtl.ca. Tel: 1.514.340.4711 x 2988. Fax: 1.514.340.5918. 


\begin{abstract}
A study was conducted to assess the impact of media aging on Cryptosporidium parvum transport and retention in granular filters. Column experiments were conducted with sand, anthracite and granular activated carbon (GAC) filters. All columns possessed an identical filter design and grain size distribution. Oocyst removal was evaluated with both new and aged media. The variation of performance amongst new media was attributed to the shape of the tested granular media and to the concentration of extractable metals on the surface of collector grains. Media aging significantly increased the treatment performance of sand $(26 \%)$ and of GAC (31\%) but had no influence on the performance of anthracite. This enhanced performance of aged media correlated well with the extent of biofilm development. The best removal performance was observed with aged GAC $(71 \pm 2 \%)$ which supported the highest amount of biomass according to polysaccharide and protein measurements. The results of this investigation are of particular interest as they suggest that media aging increases the removal of protozoan parasites in full-scale granular filters.
\end{abstract}

Subject Headings: Water treatment; granular filtration; media aging; Cryptosporidium; biofilm 


\section{Introduction}

Removal of Cryptosporidium spp. in granular media filtration has been the topic of numerous investigations as this process is a key barrier for drinking water treatment plants without UV irradiation. Although the impact of coagulation (Ongerth and Pecoraro, 1995, Patania et al., 1995, Dugan et al., 2001, Huck et al., 2002), filter design (Patania et al., 1995, Swertfeger et al., 1999) and filter operation (Nieminski and Ongerth, 1995, Patania et al., 1995, Huck et al., 2002, Emelko et al., 2003) have been given important attention, the impact of media aging on oocyst removal has received significantly less consideration. An earlier study has shown that biofilm development can hinder Cryptosporidium removal on glass beads (Dai and Hozalski, 2002). Similarly, another study revealed greater oocyst removal using fresh granular activated carbon (GAC) filters versus loaded GAC filters (Hijnen et al., 2010). Nevertheless, these studies contradict what has been reported in the literature with regards to the removal of bacteria (Liu et al., 2007, 2008, Hijnen et al., 2010), non-biological particles (Tripathi et al., 2012) and oocysts (Amburgey et al., 2005). In fact, oocysts can attach to biofilm-coated surfaces in greater numbers than on abiotic surfaces (glass without biofilm). This enhanced attachment has been associated to biofilm roughness and to the composition of extracellular polymeric substances (EPS) (Searcy et al., 2006). Moreover, it has been documented in controlled laboratory experiments that oocysts are able to attach and persist within drinking water biofilms (Helmi et al., 2008). A better understanding of the biofilm EPS composition present on the surface of aged granular media might help explain the observed discrepancies with regards to filtration performance. 
As most investigations assessing the impact of biofilm development on C. parvum removal by granular filtration were conducted with only one media type, its influence remains largely unknown. This is of importance as various porous media differ in terms of shape, roughness, metal oxides content, adsorption and capacity to be colonized. Firstly, it is known that the shape of grains influences the performance of granular filtration as different removal mechanisms come into play. For instance, physical exclusion by straining might be of greater importance when angular media is used (Tufenkji et al., 2004). Secondly, it has been documented that metal oxides on the surface of grains enhance the removal of $C$. parvum oocysts (Abudalo et al., 2005, Hijnen et al., 2005). Thirdly, as porous media age, natural organic matter (NOM) will adsorb on the surface of grains and influence filter performance. Adsorption of humic acids onto collectors hinders removal as it can lead to increased electrostatic and steric repulsion between particles and collectors (Franchi and O'Melia, 2003, Pelley and Tufenkji, 2008). Furthermore, the adsorption capacity of some porous media can enhance their capacity to be colonized. For example, GAC which is commonly used in the water industry to adsorb NOM particularly favors biofilm development (Wang et al., 1995, Magic-Knezev and van der Kooij, 2004, Prévost et al., 2005, Zhu et al., 2010). For all of the reasons stated above, we hypothesize that different types of granular media will not age in a similar fashion and, consequently, differences ought to be expected with respect to oocyst removal.

The objective of this research is to investigate the impact of new and aged media on Cryptosporidium parvum transport and retention profiles in drinking water granular filters. The scientific hypothesis of this research is that media aging, defined as increased 
biofilm development on porous media, enhances Cryptosporidium retention in granular filters. This was assessed with parallel experiments using identical sand, anthracite and GAC filters. Such increased knowledge is of use to the water industry and regulators as it supports backwashing strategies and contributes more knowledge for quantitative microbial risk assessment (QMRA) calculations.

\section{Materials and methods}

\section{Transport experiments}

Transport experiments were performed in monomedia filters (bed depth of $74 \mathrm{~cm}$ ) in PVC columns (inner diameter of $32 \mathrm{~mm}$ ) at a filtration rate of $5 \mathrm{~m} \mathrm{~h}^{-1}$. The experimental design is summarized in Table 1. All experiments were conducted with unchlorinated tap water from the St-Lawrence River, stored at room temperature, which had the following characteristics: a temperature of $20.4 \pm 0.5^{\circ} \mathrm{C}$, a pH of $8.3 \pm 0.2$, an alkalinity of $85 \pm 2$ $m g \mathrm{CaCO}_{3} \mathrm{~L}^{-1}$ and a conductivity of $300 \pm 6 \mu \mathrm{S} \mathrm{cm}^{-1}$ (Table 2). Prior to loading columns with new media (fresh media from the supplier), the grains were soaked in deionized water for 72 hours. Columns were then backwashed to allow a $40 \%$ bed expansion and flushed overnight with an oocyst free influent solution to precondition the media to the water of the St-Lawrence River (no nutrient enrichment). Prior to transport experiments, C. parvum stock solution was vortexed, diluted in influent water and agitated for 30 minutes with a stir bar to allow the conditioning (acclimation) of oocysts. Oocyst injection was conducted for 18 pore volumes (PVs) at a concentration of $750 \pm 250$ oocysts $\mathrm{mL}^{-1}$. Subsequently, the column was eluted for $12 \mathrm{PVs}$ with an oocyst free influent solution. Samples of the column influent were collected at $0,9,11,13,15,17$ 
and 30 PVs. Column effluent samples were collected at every PV. As the chosen sand, anthracite and GAC differ in terms of porosity, oocyst injection, filter elution and sampling protocols used a pore volume approach rather than the traditional time based approach in order to normalize contact times. An empty bed pore volume is defined as the volume occupied by the solution within the filter bed. In this study, the time equivalents of a PV are the following: $210 \mathrm{~s}$ (sand), $221 \mathrm{~s}$ (anthracite), $274 \mathrm{~s}$ (GAC).

\section{[TABLES _1_and_2_HERE]}

\section{Porous media}

Silica sand (Temisca Inc., Canada), anthracite (Terratech Inc., Canada) and GAC (Picabiol, H120-3D, PICA, France) were used as porous media for transport experiments. The size distribution of sand grains was assessed by sieving experiments $(n=5)$ using a Ro-Tap Sieve Shaker (W.S. Tyler, USA). Identical size distributions were then reproduced for anthracite and GAC. All media possessed an effective size $\left(d_{10}\right)$ of 650 $\mu \mathrm{m}$, median size $\left(d_{50}\right)$ of $860 \mu \mathrm{m}$ and a uniformity coefficient of 1.4 . Density and porosity of sand $\left(2.53 \mathrm{~g} \mathrm{~cm}^{-3} ; 0.35\right)$, of anthracite $\left(1.49 \mathrm{~g} \mathrm{~cm}^{-3} ; 0.40\right)$ and of GAC (dry $0.39 \mathrm{~g} \mathrm{~cm}^{-3}$, wet $\left.1.25 \mathrm{~g} \mathrm{~cm}^{-3} ; 0.45\right)$ were determined by gravimetric methods.

\section{Media aging}

Media aging results from media ripening and/or a modification of media surface properties due to abiotic factors (e.g. metal deposition) and/or biofilm development. In this study, the experimental design was conceived to assess the impact of biofilm development on oocyst removal by granular filtration. For each granular medium investigated, two replicate monomedia filters were fed during 18 weeks at a superficial velocity of $5 \mathrm{~m} \mathrm{~h}^{-1}$ with unchlorinated tap water from the St-Lawrence River at a 
temperature of $20.4 \pm 0.5^{\circ} \mathrm{C}$. Biofilm growth on the filter media was promoted by amending the influent water with a nutrient solution composed of sodium acetate $(1 \mathrm{mg} \mathrm{C}$ $\left.\mathrm{L}^{-1}\right), \mathrm{NH}_{4} \mathrm{Cl}\left(0.1 \mathrm{mg} \mathrm{N} \mathrm{L}^{-1}\right)$ and $\mathrm{K}_{2} \mathrm{HPO}_{4}\left(0.01 \mathrm{mg} \mathrm{P} \mathrm{L}^{-1}\right)$ during 18 weeks. One set of replicate sand columns was not amended with nutrients but instead chlorinated at $2 \mathrm{mg}$ $\mathrm{Cl}_{2} \mathrm{~L}^{-1}$ (as free chlorine) throughout the same period to allow media aging under unfavorable conditions for biofilm development.

\section{Media characterization}

Metals on new and aged media were extracted according to Method 3050 (United States Environmental Protection Agency, 1996) and analyzed by inductively coupled plasma atomic emission spectrometry (ICP-AES) according to Method 6010B (USEPA 1996). Media grains were also imaged with a scanning electron microscope (SEM) (JSM 840A, JEOL) to assess the impact of aging on their shape and structure.

Spatial distribution of the biomass was assessed by core sampling the filter beds at various depths. Biofilm constituents such as polysaccharides and proteins were quantified to better understand the role of biofilm from a biochemical perspective. Samples were placed in a centrifuge tube containing sterile phosphate buffered water. Polysaccharides and proteins were extracted from the filter media by formaldehyde $\left(36.5 \%, 4^{\circ} \mathrm{C}, 1 \mathrm{~h}\right)$ followed by $\mathrm{NaOH}\left(1 \mathrm{~N}, 4^{\circ} \mathrm{C}, 3 \mathrm{~h}\right)$ (Liu and Fang, 2002). The polysaccharide and protein suspension was purified by high-speed centrifugation $\left(12,000 g, 15\right.$ minutes, $\left.4^{\circ} \mathrm{C}\right)$. The supernatant was filtered through a $0.45 \mu \mathrm{m}$ pore-size membrane, placed in sterilized tubes and stored at $-18^{\circ} \mathrm{C}$. Extracted polysaccharides were quantified by the phenol-sulphuric acid method (DuBois et al., 1956) with D-glucose as a standard. Total proteins were quantified by colorimetric detection based on bicinchoninic 
acid (Pierce BCA Protein Assay kit, Thermo Scientific, USA) with bovine serum albumin as a standard.

\section{Cryptosporidium oocysts}

Cryptosporidium parvum oocysts, Iowa isolate (bovine origin) were purchased from

Waterborne Inc., USA. The oocysts were purified by the supplier using a sucrose and Percoll density gradient and placed in $1 \mathrm{X}$ phosphate buffered saline (PBS) with antibiotics (penicillin, streptomycin, gentamicin, amphotericin B) and $0.01 \%$ Tween 20 . The oocysts were irradiated by low pressure UV lamps at a dose of $50 \mathrm{~mJ} \mathrm{~cm}^{-2}$ by Tetratech Inc., USA. The stock solution was diluted in sterile 1X PBS to a concentration of $6.0 \times 10^{5}$ oocysts $\mathrm{mL}^{-1}$ and stored in the dark at $4^{\circ} \mathrm{C}$.

The electrophoretic mobility of a suspension of $10^{6}$ oocysts $\mathrm{mL}^{-1}$ in tap water at $20^{\circ} \mathrm{C}$ was measured using a Zetasizer Nano (Malvern Instruments Ltd., UK).

Electrophoretic mobilities were converted to zeta potentials using the Smoluchowski equation (Hunter, 2001). The calculated zeta potential was found to be $-6.5 \pm 1.7 \mathrm{mV}$.

\section{Cryptosporidium enumeration}

Samples of suspended oocysts were filtered onto a $2 \mu \mathrm{m}$ pore-size membrane (ChemFilter CB 2.0, AES Chemunex Inc., France). Oocysts were stained with fluorescein isothiocyanate (FITC) labeled monoclonal antibodies (Easy stain, BTF Ltd., Australia). Each membrane was placed on $100 \mu \mathrm{L}$ of labeling solution and incubated at $37^{\circ} \mathrm{C}$ for an hour. Oocysts were enumerated by laser scanning cytometry (ScanRDI, AES Chemunex Inc., France) (Stanfield et al., 2000) and confirmed by a microscopic examination at a magnification of 600X (BX 60, Olympus Inc., Japan). Colorseeds (BTF Ltd., Australia) were spiked as described by the supplier in an oocyst free sample 
(influent or effluent) to evaluate the recovery and precision of the enumeration method for every media type and age.

\section{Assessment of retained oocysts and mass balance calculations}

After deloading (elution with an oocyst free influent solution) (i.e., $30 \mathrm{PVs}$ ), the spatial distribution of oocysts inside the filter bed was assessed by core sampling at different depths. The extraction protocols used to detach oocysts from the filter media were inspired by (Hijnen et al., 2010) and were optimized for each media type in order to maximize the number of enumerated oocysts (based on enumeration). Sand samples were treated successively by hand shaking ( 2 min.), vortex mixing ( 2 min.) and low intensity sonication in a sonication bath ( $2 \mathrm{~min}$.). Anthracite samples were treated by hand shaking ( $2 \mathrm{~min}$.) followed by vortex mixing ( $2 \mathrm{~min}$.). As for GAC samples, they were only treated by hand shaking ( $2 \mathrm{~min}$.) as further vortexing or sonication reduced recovery due to the formation of GAC fines. Once the extraction protocol was completed, the supernatant was immediately removed and placed in a sterilized tube for oocyst enumeration. To evaluate the recovery of the retained oocysts, a mass balance was calculated as described below:

$$
\begin{aligned}
& N_{\text {inf luent }}=N_{\text {effluent }}+N_{\text {filter_bed }}=t \overline{C_{0}} Q \\
& N_{\text {effluent }}=\sum_{i=1}^{30} V_{P V}\left(\frac{C_{i}+C_{i+1}}{2}\right) \\
& N_{\text {filter_bed }}=\sum_{x=0}^{x=L}\left(\frac{\left|C_{x}+C_{x+1}\right|}{2}\right)\left(\frac{x_{i+1}-x_{i}}{L} M_{t}\right)
\end{aligned}
$$

where $N$ the number of Cryptosporidium oocysts, $t$ is the duration of continuous oocyst injection (min), $C_{0}$ the mean influent concentration of suspended oocysts (oocysts $\mathrm{mL}^{-1}$ ), $Q$ the flow rate $\left(\mathrm{mL} \mathrm{min}^{-1}\right), V_{p v}$ the volume of water per PV $(\mathrm{mL}), C_{i}$ the effluent 
concentration of suspended oocysts at pore volume $i$ (oocysts $\mathrm{mL}^{-1}$ ), $C_{x}$ the number of oocysts per gram of dry media at the depth $x(\mathrm{~cm}), L$ the total column length $(\mathrm{cm})$ and $M_{t}$ the total mass of dry media contained in the column $(\mathrm{g})$. The recovery of the extraction protocol (\%) was calculated as described below:

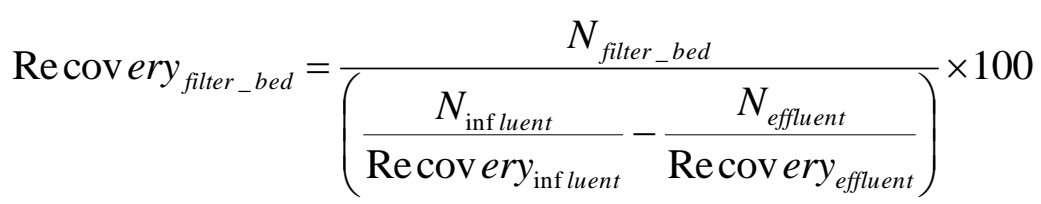

where, the recovery of the oocyst enumeration method in both influent and effluent waters were assessed using colorseeds ${ }^{\mathrm{TM}}$. Here, it was hypothesized that oocyst removal due to predation by higher organisms was negligible due to the short duration of the transport experiments.

\section{Calculation of retention profiles}

The profile of retained oocysts, $S(x)$, as described by the classical colloid filtration theory (CFT) can be estimated as follows (Yao et al., 1971):

$$
S(x)=\frac{t_{0} \theta k_{d} C_{0}}{\rho_{b}} \exp \left(\frac{-k_{d}}{v} x\right)
$$

where $t_{0}$ is the duration of continuous oocyst injection (s), $\theta$ the bed porosity (unitless), $k_{\mathrm{d}}$ the particle deposition rate coefficient $\left(\mathrm{sec}^{-1}\right), C_{0}$ the influent oocyst concentration (oocyst $\left.\mathrm{mL}^{-1}\right), \rho_{\mathrm{b}}$ the media bulk density $\left(\mathrm{g} \mathrm{cm}^{-3}\right), v$ the fluid approach velocity $\left(\mathrm{cm} \mathrm{s}^{-1}\right)$ and $x$ the column depth $(\mathrm{cm})$. The oocyst retention profiles $(S(x))$ were calculated for each experiment.

\section{Statistical analysis}

For each replicate column, removals were calculated using four paired influent/effluent samples at steady state. For one media condition, mean performance was assessed by 
pooling paired sample from replicate columns. Unless otherwise noted, paired t-test or ANOVA analysis was conducted on oocyst removal (expressed as percentage) using Statistica 9.0 (Statsoft, USA). Removals in percentage rather than log removals were selected for the statistical analysis as log removal residuals did not exhibit a normal distribution as opposed to removal residuals expressed in percentage.

\section{Results}

\section{Seasonal performance of new media}

Initially, the experimental plan was scheduled to be completed over two seasons: summer and fall. However, a seasonal variation of removal efficiencies was observed between transport experiments conducted with new media during these two seasons (Fig. 1). Oocyst removal was significantly lower during fall than during summer $(p<0.05)$. In summer, sand had the poorest performance $(54 \pm 4 \%)$ while GAC offered the greatest oocyst removal $(89 \pm 1 \%)$. During fall, sand also offered the lowest performance $(p<$ 0.05) of the tested media while similar removal efficiencies were observed for anthracite and $\operatorname{GAC}(p=0.11)$.

\section{[FIG._1_HERE]}

Seasonal water quality parameters were assessed in order to evaluate their potential contribution to this variability (Table 2). Total organic carbon (TOC) proved to be the only parameter that significantly differed between both seasons amongst the evaluated parameters. Because experiments with aged media were conducted during the fall, the comparison of performance between new and aged media (presented in Fig. 2) was done with data obtained during the same season. 


\section{Impact of media aging on oocyst removal}

Media aging significantly improved the performance of sand and GAC $(p<0.05)$ but had no impact on the performance of anthracite $(p=0.81)$ (Fig. 2). Media aging in the presence of pre-chlorination also significantly improved $(p<0.05)$ the performance of sand columns although significantly less than when aged in absence of pre-chlorination $(p<0.05)$. Furthermore, the performance of aged sand and aged anthracite columns did not differ $(p=0.22)$. In contrast, aged GAC proved to be the most efficient of all tested conditions for the removal of Cryptosporidium oocysts $(71 \pm 2 \%)$. Finally, as portrayed by the breakthrough curves (Fig. 3) all experiments reached a plateau and were conducted at steady state.

\section{[FIG._2_and_3_HERE]}

\section{Mass balance of oocysts}

Mass balance calculations (Table 3) demonstrate that the established extraction protocol to detach oocysts from collectors was suitable for anthracite (87-92\%) and new GAC (90\%). As for sand, the extraction procedure caused an overestimation of the attached oocysts for all cases (> 100\%). This overestimation can be explained by the low number of retained oocysts by sand filters as well as the total volume of extracted granular media $(1.2 \pm 0.5 \%$ of the filter bed) used to evaluate the number of retained oocysts within the filter bed. These experimental conditions resulted in greater calculation error and consequently to an overestimation of the number of oocysts retained within the filter bed of sand filters. Lastly, the protocol used to detach oocysts from GAC grains offered the lowest recovery when used on aged media (36\%). The recoveries of all tested extraction protocols were higher when used on new media compared to aged media. 


\section{[TABLE_3_HERE]}

\section{Retention profiles}

Measured oocyst retention profiles (Fig. 4) demonstrate that a greater portion of oocysts was retained in the top layer of the filter bed (near the inlet). Namely, oocyst retention in the top layer $(15 \mathrm{~cm})$ of the filter bed, expressed in percentage of the total retention, occurred to a greater extent in GAC columns (new 48\%; aged 56\%) than in sand (new 35\%; aged 39\%) and anthracite columns (new 36\%; aged 39\%). Furthermore, after corrections for the recovery of extraction protocols, the oocyst concentrations in the upper portion of aged sand, anthracite and new GAC filters exceeded predictions based on the classical CFT. Finally, sieving experiments confirmed that subsequent to backwash, smaller grains accumulated in the top layer of the filter (Fig. A1, Appendix). Hence, factors not considered in the classical CFT, such as grain size heterogeneity may also be influencing the oocyst retention behavior. This would explain the notable variation between the experimental measurements and the retained oocyst profiles predicted by colloid filtration theory (in Fig. 4).

\section{[FIG._4_HERE]}

\section{Metal oxides}

The total concentration of extracted metals (Table 4) differed between media types, but independently of their age $(p<0.05)$. Sand possessed the least amount of extractable metals. Anthracite possessed the greatest concentrations of aluminum and iron and GAC had the greatest concentration of total extractable metals due to its remarkably high calcium concentration. Media aging had no impact on the sum of extractable metals of sand $(p=0.62)$ and of anthracite $(p=0.32)$. Moreover, no differences were observed 
between aged sand and aged pre-chlorinated sand $(p=0.97)$. In contrast, media aging slightly increased $(13 \%)$ the total concentration of extractable metals for GAC $(p<0.05)$.

[TABLE_4_HERE]

\section{Biofilm development}

Significant differences in biofilm biomass were observed between GAC and other tested media. Aged GAC supported the highest amount of biomass whereas no differences were observed between aged sand and aged anthracite. In addition, distribution profiles (Fig. 5) demonstrate that both polysaccharide (PS) and protein (P) concentrations were more abundant in the upper portion of the filter bed (near the inlet). The two EPS measurements (PS and P), were highly correlated $(r=0.96)$. The magnitude biofilm development observed in this investigation was validated with full-scale data. The polysaccharide and protein measurements in the upper portion of the GAC filter bed proved to be in the same order of magnitude than to those assessed in full-scale GAC filters (PS pilot: $2 \mathrm{mg} / \mathrm{g}$ vs PS full scale: $5 \mathrm{mg} / \mathrm{g}$ and $\mathrm{P}_{\text {pilot: }} 3 \mu \mathrm{g} / \mathrm{g}$ vs $\mathrm{P}_{\text {full-scale: }} 8 \mu \mathrm{g} / \mathrm{g}$ ). In addition, biofilm development did not induce variations in filter hydraulics as no significant head loss increase or modifications to the tracer breakthrough curves were observed (results not shown). This shows that the chosen media aging conditions proved to be realistic and conservative in terms of biofilm development. Finally, all new media differed in terms of shape (Fig. 6) but the impact of biofilm development on the shape of collectors was only noticeable on GAC grains where the structure of macropores was covered by the biomass (Fig. 7).

[FIG._5_6_and_7_HERE] 


\section{Discussion}

\section{Oocyst removal by new media: Impact of media type}

Seasonal variations of performance

Water quality proved to significantly differ in terms of TOC concentration between summer and fall. We hypothesize that the small but significant increase in TOC concentration led to the observed decrease in Cryptosporidium removal. These results are concurrent with previous studies that demonstrated that dissolved organic carbon hindered oocyst removal by granular filtration (Dai and Hozalski, 2002, Abudalo et al., 2010, Metge et al., 2010). For example, influent water amended with $5 \mathrm{mg} \mathrm{L}^{-1}$ of Suwannee River NOM (SRNOM) caused a 37\% decrease in Cryptosporidium removal in columns packed with glass beads (Dai and Hozalski, 2002). Similarly, the addition of 2.2 $\mathrm{mg} \mathrm{L}^{-1}$ of DOC to influent water caused a 36\% decrease in oocyst removal (Metge et al., 2010). This reduction in performance can be explained by the adsorption of NOM onto collector surfaces. The attachment of negatively charged humic acids onto grains increases the electrostatic and steric repulsion between particles and collectors (Franchi and O'Melia, 2003). Moreover, the adsorption of DOC onto metal oxides may result in charge reversal of these favorable patches on collector grain surfaces. For instance, low concentrations of fulvic acids $\left(<1.9 \mathrm{mg} \mathrm{L}^{-1}\right)$ caused a charge reversal of ferric oxyhydroxide coated sand and resulted in an increased breakthrough of oocysts (Abudalo et al., 2010). The impact of NOM on Cryptosporidium transport can also be associated with the adsorption of NOM onto oocysts (Tufenkji et al., 2006). It has been documented that oocysts treated with SRNOM $\left(5 \mathrm{mg} \mathrm{L}^{-1}, 30 \mathrm{~min}\right.$.) were more negatively charged and possessed a higher hydrophobicity than untreated oocysts. The authors suggested that 
these changes in surface properties led to the observed decreased Cryptosporidium attachment (Dai and Hozalski, 2002). However, no significant seasonal differences in zeta potential were observed in the current study. Similarly, no differences in zeta potential were observed for oocysts treated with fulvic acids up to a concentration of 20 $\mathrm{mg} \mathrm{L}^{-1}$ (Abudalo et al., 2010). However, the decreased deposition due to the adsorption of NOM onto oocysts is not only attributable to an increase in the absolute value of the zeta potential, steric interactions also play an important role in the deposition of oocysts onto collector surfaces (Kuznar and Elimelech, 2006, Tufenkji et al., 2006). Namely, adsorption of DOC onto both oocyst and collector surfaces can contribute to the overall extent of electrosteric interactions as oocysts approach a media grain. In summary, data from this study suggest that the increase in TOC concentration during fall did impair oocyst removal by new media. Of the tested media, GAC was the most sensitive to TOC variations, likely due to its higher affinity for TOC. Based on these seasonal variations of performance due to TOC concentrations, our results suggest that TOC alters the surface properties of collectors and oocysts and consequently decreases the deposition of Cryptosporidium onto new media.

\section{Impact of porosity and shape of collectors}

All tested granular media possessed the same size distribution and median diameter but differed in terms of porosity and shape/roughness. Sand columns possessed the smallest porosity and offered the lowest removal efficiency. In contrast, significantly higher oocyst removals were measured using anthracite and GAC filters. It is interesting to note that both media possessed a greater porosity, roughness and angularity than sand (Fig. 6). These results agree with previous observations that demonstrated that grain shape 
impacts the removal of oocysts as physical removal is of greater importance when angular media are used (Tufenkji et al., 2004). Physical exclusion by straining/wedging has been reported to take place when the particle:collector ratio $\left(d_{\mathrm{p}} / d_{\mathrm{c}}\right)$ is greater than 0.005 (Bradford et al., 2003, 2006, Johnson et al., 2007). In this investigation, the oocyst-to-collector size ratio proved to be equivalent to this reported threshold value $\left(d_{\mathrm{p}} / d_{\mathrm{c}}=0.005\right)$. Hence, straining/wedging should not be a dominant removal mechanism under these experimental conditions. However, results obtained by sieving experiments confirmed that the oocyst-to-collector size ratio $\left(d_{\mathrm{p}} / d_{\mathrm{c}}\right)$ in the upper layer (0-20\% deep; $15 \mathrm{~cm})$ of the filter bed was slightly superior to $0.005\left(d_{\mathrm{p}} / d_{\mathrm{c}}\right.$ of sand: 0.006 , anthracite: 0.006 and GAC: 0.008) (Table A.1, Appendix). Therefore, straining/wedging might account for some of the removal as finer grains tend to accumulate in the top layer of the filter bed subsequent to the backwashing procedure. Yet, as revealed by the seasonal variations of performance of new media due to changes in TOC concentration, removal by physical exclusion by straining/wedging cannot solely explain the observed difference in performance amongst new media. Chemical properties of the collectors also play an important role with regards to oocyst transport and removal.

\section{Metal content}

An increase in metal content of granular media improved oocyst removal by new media. Consequently, the significantly higher aluminum and iron content of anthracite led to an increased performance of anthracite over sand. This observation corroborates previous studies which have documented that Cryptosporidium removal is a function of aluminum and iron oxides on the surface of collectors (Abudalo et al., 2005, Metge et al., 2010). Accordingly, GAC, which possessed the highest metal concentration, offered the best 
performance in summer. This trend was not observed during fall. GAC likely has a higher adsorption capacity for TOC, which may mask metal oxide patches on grain surfaces (as discussed above). In conclusion, results of this study suggest that metals present on the surface of collectors play a key role in oocyst deposition onto new media.

\section{Oocyst retention profiles}

The oocyst retention profiles of both new and aged media proved to be non-log-linear as opposed to the exponential profiles predicted by colloid filtration theory. This disagreement between retained microorganism profiles and data predicted by classical CFT has been reported by other authors (Tufenkji and Elimelech, 2005, Liu et al., 2007). These discrepancies were expected as experiments were conducted under unfavorable conditions for oocyst deposition (high $\mathrm{pH}$ and low ionic strength). Although data obtained from sieving experiments were used to correct the retention profiles according to the classical CFT using the median size of each layer, this correction had no significant influence on the predicted retention profiles (Fig. A2, Appendix). In addition, the oocystto-collector size ratio $\left(d_{\mathrm{p}} / d_{\mathrm{c}}\right)$ in the upper layer of the filter bed was slightly superior to 0.005. Therefore, straining/wedging may account for some of the discrepancies between the observed and predicted retention profiles (Bradford et al., 2003, Johnson et al., 2007) of new and aged media. Finally, variations in the extent of biomass development on the surface of collector grains as a function of filter depth will also account for the observed deviation from classical CFT. These results demonstrate that more research is needed to integrate filter bed heterogeneity as a function of depth in colloid filtration models to better predict oocyst retention behavior in engineered systems. 
The performance of extraction protocols used to assess oocyst retention profiles was not always optimal. Special attention should be paid to GAC and aged media as lower recoveries were observed for these conditions in the current study. The energy used on GAC grains was not sufficient to extract oocysts but was enough to produce GAC fines. These particles created some interference during microscopic examination as they adsorbed FITC during oocyst staining. This caused background fluorescence which made the detection of oocysts less efficient. Moreover, low intensity sonication of sand grains may have damaged oocysts and produced artifacts (oocyst debris) that resulted in an overestimation of oocysts on this material. As the observed values of retained oocysts within filter beds was either underestimated (for aged GAC) or overestimated (for sand), no statistical analysis was performed to correlate $S(x)$ with biofilm density. Our results highlight the importance of conducting mass balance calculations when comparing the retention profiles of different media type. In summary, the use of accurate data is of importance to understand Cryptosporidium retention in industrial systems and special attention should be paid to recoveries of extraction protocols on filter media.

\section{Impact of media aging}

The results of the current study confirm that media aging significantly improved Cryptosporidium removal. These findings are of importance as other studies have demonstrated that biofilm development on the surface of granular media hinders the removal of oocysts (Dai and Hozalski, 2002, Hijnen et al., 2010). Firstly, it should be noted that this investigation assessed Cryptosporidium removal with wood based GAC and did not inject any other microorganism in influent water contrarily to the study by (Hijnen et al., 2010) which assessed Cryptosporidium removal not only with coal-based 
GAC but also simultaneously injected Cryptosporidium oocysts, MS2 phages, E.coli, spores of C.bifermentans and Giardia cysts. Moreover, the GAC (coal-based) used in the earlier study was aged under less favorable conditions for biomass development than in the current study. Therefore, the opposite performance trends observed in this study may be explained by differences in the surface properties of wood and coal-based GAC and/or by greater biofilm abundance in this study due to more favorable aging conditions (nutrient amendment in feed water). Secondly, contrary to lab scale experiments conducted in columns packed with glass beads coated with Pseudomonas aeruginosa biofilm (Dai and Hozalski, 2002), the chosen experimental conditions promoted the development of biofilm formed by autochthonous bacteria. This may have had an impact on oocyst removal as it has been demonstrated that EPS production is not only influenced by environmental stress (Morales et al., 2010) but also varies from one bacterial strain to another (Flemming and Wingender, 2001, Liu et al., 2008). As a result, the nature of the EPS constituents and biofilm thickness on granular media may improve or impair microbial deposition (Liu and Li, 2008, Liu et al., 2008). Data from the present study demonstrate that biofilm development which occurs during filter operation increases oocyst removal by granular filters. This increased Cryptosporidium retention is also indirectly supported by the lower filter bed oocyst recovery of aged media (as discussed above). These observations are also concurrent with previously reported data where biofilm development proved to decrease the zeta potential of sand and as a result increased latex particle and quantum dots retention (Tripathi et al., 2012). Amongst the tested media, biofilm development on GAC grains was the most remarkable. Moreover, the distribution of EPS constituents as a function of depth of GAC filters was typical of 
vertical profiles of bacterial biomass reported in the literature (Servais et al., 1991, Moll and Summers, 1999). Indeed, several other researchers have documented that macroporous GAC generally supports a higher biomass than sand and anthracite (Wang et al., 1995, Prévost et al., 2005). This can be explained by the surface area of GAC grains (Prévost et al., 2005), by its irregular shape which protects biomass from shear stress (Rittmann, 1982) and by backwashing procedures. Due to the density of GAC, lower energy backwash is needed to ensure proper bed expansion. Consequently, less detachment of the fixed biomass occurs during backwash as GAC grains are exposed to lower shear forces (Rittmann, 1982) than sand or anthracite. For the reasons listed above, in the current study, GAC supported the greatest amount of biomass and also offered the best oocyst removal.

Interestingly, media aging improved the performance of sand but had no impact on the performance of anthracite despite the fact that both granular media supported the same amount of biomass. Therefore, biomass does not seem to impact the performance of anthracite and another removal mechanism seems to be driving Cryptosporidium deposition onto this material. Thus, more research is needed to gain more knowledge with regards to oocyst deposition on anthracite. As a final comment, the impact of biofilm development on oocyst retention and release during extended periods was not assessed by this experimental design. An improved understanding of the impact of biofilm development on oocyst detachment could lead to recommendations on granular filter operation to minimize oocyst breakthrough. 


\section{Summary and conclusions}

This study is the first to present the impact of media aging on Cryptosporidium retention using three different media types tested under identical experimental conditions. Our results demonstrate that the removal of oocysts by new media is sensitive to seasonal variations of TOC concentration. Media aging improved the performance of sand and GAC filters. The best performance was observed with aged GAC filters which harbored the greatest amount of biomass according to EPS measurements. Considering the high interest of the water treatment industry for GAC treatment, further studies are needed to validate if these results are dependent on GAC composition, grain angularity and/or roughness.

\section{Acknowledgement}

The authors acknowledge the Industrial NSERC Chair in Drinking Water and its industrial partners, namely the City of Montreal, John Meunier Inc. and the City of Laval. The authors wish to thank the Chair's personnel for their support and technical assistance in the laboratory work. In addition, they thank Prof. G. A. Vàzquez-Rodríguez (Universidad Autónoma del Estado de Hidalgo) for the biomass measurements in fullscale GAC filters. The authors would also like to acknowledge the financial support of the Canadian Water Network and the Canada Research Chairs program. 


\section{References}

Abudalo, R. A., Bogatsu, Y. G., Ryan, J. N., Harvey, R. W., Metge, D. W., and Elimelech, M. (2005). "Effect of ferric oxyhydroxide grain coatings on the transport of bacteriophage PRD1 and Cryptosporidium parvum oocysts in saturated porous media." Environ. Sci. Technol., 39(17), 6412-6419.

Abudalo, R. A., Ryan, J. N., Harvey, R. W., Metge, D. W., and Landkamer, L. (2010). "Influence of organic matter on the transport of Cryptosporidium parvum oocysts in a ferric oxyhydroxide-coated quartz sand saturated porous medium." Water Res., 44(4), 1104-1113.

Amburgey, J. E., Amirtharajah, A., York, M. T., Brouckaert, B. M., Spivey, N. C., and Arrowood, M. J. (2005). "Comparison of conventional and biological filter performance for Cryptosporidium and microsphere removal." J. Am. Water Works Assoc., 97(12), 77-91.

Bradford, S. A., Simunek, J., Bettahar, M., van Genuchten, M. T., and Yates, S. R. (2003). "Modeling colloid attachment, straining, and exclusion in saturated porous media." Environ. Sci. Technol., 37(10), 2242-2250.

Bradford, S. A., Simunek, J., Bettahar, M., van Genuchten, M. T., and Yates, S. R. (2006). "Significance of straining in colloid deposition: evidence and implications." Water Resour. Res., 42(12), 12-15.

Dai, X., and Hozalski, R. M. (2002). "Effect of NOM and biofilm on the removal of Cryptosporidium parvum oocysts in rapid filters." Water Res., 36(14), 3523-3532.

DuBois, M., Gilles, K. A., Hamilton, J. K., Rebers, P. A., and Smith, F. (1956). "Colorimetric Method for Determination of Sugars and Related Substances." Analytical Chemistry, 28(3), 350-356.

Dugan, N. R., Fox, K. R., Owens, J. H., and Miltner, R. J. (2001). "Controlling Cryptosporidium oocysts using conventional treatment." J. Am. Water Works Assoc., 93(12), 64-76.

Emelko, M. B., Huck, P. M., and Douglas, I. P. (2003). "Cryptosporidium and microsphere removal during late in-cycle filtration." J. Am. Water Works Assoc., 95(5), 173-182.

Flemming, H. C., and Wingender, J. (2001). "Relevance of microbial extracellular polymeric substances (EPSs) - Part II: technical aspects." Water Sci. Technol., 43(6), 9-16.

Franchi, A., and O'Melia, C. R. (2003). "Effects of natural organic matter and solution chemistry on the deposition and reentrainment of colloids in porous media." Environ. Sci. Technol., 37(6), 1122-1129.

Helmi, K., Skraber, S., Gantzer, C., Willame, R., Hoffmann, L., and Cauchie, H.-M. (2008). "Interactions of Cryptosporidium parvum, Giardia lamblia, Vaccinal Poliovirus Type 1, and bacteriophages $\phi X 174$ and MS2 with a drinking water biofilm and a wastewater biofilm." Appl. Environ. Microbiol., 74(7), 2079-2088.

Hijnen, W. A. M., Brouwer-Hanzens, A. J., Charles, K. J., and Medema, G. J. (2005). "Transport of MS2 phage, Escherichia coli, Clostridium perfringens, Cryptosporidium parvum, and Giardia intestinalis in a gravel and a sandy soil." Environ. Sci. Technol., 39(20), 7860-7868. 
Hijnen, W. A. M., Suylen, G. M. H., Bahlman, J. A., Brouwer-Hanzens, A., and Medema, G. J. (2010). "GAC adsorption filters as barriers for viruses, bacteria and protozoan (oo)cysts in water treatment." Water Res., 44(4), 1224-1234.

Huck, P. M., Coffey, B. M., Emelko, M. B., Maurizio, D. D., Slawson, R. M., Anderson, W. B., Van Den Oever, J., Douglas, I. P., and O'Melia, C. R. (2002). "Effects of filter operation on Cryptosporidium removal." J. Am. Water Works Assoc., 94(6), 97-111.

Hunter, R. J. (2001). Foundations of colloid science (Second Edition), Oxford University Press, Oxford, Toronto, Canada.

Johnson, W. P., Li, X., and Yal, G. (2007). "Colloid retention in porous media: mechanistic confirmation of wedging and retention in zones of flow stagnation." Environ. Sci. Technol., 41(4), 1279-1287.

Kuznar, Z. A., and Elimelech, M. (2006). "Cryptosporidium oocyst surface macromolecules significantly hinder oocyst attachment." Environ. Sci. Technol., 40(6), 1837-1842.

Liu, H., and Fang, H. H. P. (2002). "Extraction of extracellular polymeric substances (EPS) of sludges." J. Biotech., 95(3), 249-256.

Liu, Y., and Li, J. (2008). "Role of Pseudomonas aeruginosa biofilm in the initial adhesion, growth and detachment of Escherichia coli in porous media." Environ. Sci. Technol., 42(2), 443-449.

Liu, Y., Yang, C.-H., and Li, J. (2007). "Influence of extracellular polymeric substances on Pseudomonas aeruginosa transport and deposition profiles in porous media." Environ. Sci. Technol., 41(1), 198-205.

Liu, Y., Yang, C.-H., and Li, J. (2008). "Adhesion and retention of a bacterial phytopathogen Erwinia chrysanthemi in biofilm-coated porous media." Environ. Sci. Technol., 42(1), 159-165.

Magic-Knezev, A., and van der Kooij, D. (2004). "Optimisation and significance of ATP analysis for measuring active biomass in granular activated carbon filters used in water treatment." Water Res., 38(18), 3971-3979.

Metge, D. W., Harvey, R. W., Aiken, G. R., Anders, R., Lincoln, G., and Jasperse, J. (2010). "Influence of organic carbon loading, sediment associated metal oxide content and sediment grain size distributions upon Cryptosporidium parvum removal during riverbank filtration operations, Sonoma County, CA." Water Res., 44(4), 1126-1137.

Moll, D. M., and Summers, R. S. (1999). "Assessment of drinking water filter microbial communities using taxonomic and metabolic profiles." Water Sci. Technol., 39(7), 83-90.

Morales, V. L., Parlange, J.-Y., and Steenhuis, T. S. (2010). "Are preferential flow paths perpetuated by microbial activity in the soil matrix? A review." J. Hydrol., 393(1-2), 29-36.

Nieminski, E. C., and Ongerth, J. E. (1995). "Removing Giardia and Cryptosporidium by conventional treatment and direct filtration." J. Am. Water Works Assoc., 87(9), 96-106.

Ongerth, J. E., and Pecoraro, J. P. (1995). "Removing Cryptosporidium using multimedia filters." J. Am. Water Works Assoc., 87(12), 83-89. 
Patania, N. L., Jacangelo, J. G., Cummings, L., Wilczak, A., Riley, K., and Oppenheimer, J. (1995). "Optimization of filtration for cyst removal." American Water Works Asssociation Research Foundation, Denver, Colorado, USA, 158.

Pelley, A. J., and Tufenkji, N. (2008). "Effect of particle size and natural organic matter on the migration of nano- and microscale latex particles in saturated porous media." Journal of Colloid and Interface Science, 321(1), 74-83.

Prévost, M., Laurent, P., Servais, P., and Joret, J.-C. (2005). Biodegradable organic matter in drinking water treatment and distribution (First Edition), American Water Works Association, Denver, Colorado, USA.

Rittmann, B. E. (1982). "The effect of shear stress on biofilm loss rate." Biotech. Bioeng., 24(2), 501-506.

Searcy, K. E., Packman, A. I., Atwill, E. R., and Harter, T. (2006). "Capture and retention of Cryptosporidium parvum oocysts by Pseudomonas aeruginosa biofilms." Appl. Environ. Microbiol., 72(9), 6242-6247.

Servais, P., Billen, G., Ventresque, C., and Bablon, G. P. (1991). "Microbial activity in GAC filters at the Choisy-le-Roi treatment plant." J. Am. Water Works Assoc., 83(2), 62-68.

Stanfield, G., Carrington, E., Albinet, F., Compagnon, B., Dumoutier, N., Hambsch, B., Lorthioy, A., Medema, G., Pezoldt, H., de Roubin, M.-R., de Lohman, A., and Whitmore, T. (2000). "An optimised and standardised test to determine the presence of the protozoa Cryptosporidium and Giardia in water." Water Sci. Technol., 41(7), 103-110.

Swertfeger, J., Metz, D. H., DeMarco, J., Braghetta, A., and Jacangelo, J. G. (1999). "Effect of filter media on cyst and oocyst removal." J. Am. Water Works Assoc., 91(9), 90-100.

Tripathi, S., Champagne, D., and Tufenkji, N. (2012). "Surface Coatings in Granular Porous Media coated with Pseudomonas aeruginosa Biofilm." Environ. Sci. Technol., 46(13), 6942-6949.

Tufenkji, N., Dixon, D. R., Considine, R., and Drummond, C. J. (2006). "Multi-scale Cryptosporidium/sand interactions in water treatment." Water Res., 40(18), 33153331.

Tufenkji, N., and Elimelech, M. (2005). "Spatial distributions of Cryptosporidium oocysts in porous media: evidence for dual mode deposition." Environ. Sci. Technol., 39(10), 3620-3629.

Tufenkji, N., Miller, G. F., Ryan, J. N., Harvey, R. W., and Elimelech, M. (2004). "Transport of Cryptosporidium oocysts in porous media: role of straining and physicochemical filtration." Environ. Sci. Technol., 38(22), 5932-5938.

United States Environmental Protection Agency, U. (1996). "Method 3050B: Acid Digestion of Sediments, Sludges and Soils."Washington, D.C., USA, 12.

Wang, J. Z., Summers, R. S., and Miltner, R. J. (1995). "Biofiltration performance: part 1, relationship to biomass." J. Am. Water Works Assoc., 87(12), 55-63.

Yao, K.-M., Habibian, M. T., and O'Melia, C. R. (1971). "Water and waste water filtration: concepts and applications." Current Research, 5(11), 1105-1112.

Zhu, I. X., Getting, T., and Bruce, D. (2010). "Review of biologically active filters in drinking water applications." J. Am. Water Works Assoc., 102(12), 67-77. 
Table 1. Experimental design (number of transport experiments ${ }^{1}$ )

\begin{tabular}{|c|c|c|c|c|}
\hline \multirow{3}{*}{ Media Type } & \multicolumn{4}{|c|}{ Media Aging Condition } \\
\hline & \multicolumn{2}{|c|}{$\begin{array}{c}\text { New } \\
(0 \text { weeks })\end{array}$} & \multirow{2}{*}{$\begin{array}{l}\text { Aged with } \\
\text { nutrient solution }{ }^{2} \\
(18 \text { weeks })^{4}\end{array}$} & \multirow{2}{*}{$\begin{array}{c}\text { Aged with } \\
\text { pre-chlorination } \\
\text { without } \\
\text { nutrient solution } \\
(18 \text { weeks })^{4}\end{array}$} \\
\hline & Summer & Fall & & \\
\hline Sand & 1 & 2 & 2 & 2 \\
\hline Anthracite & 1 & 2 & 2 & --- \\
\hline GAC & 1 & 1 & 2 & --- \\
\hline $\begin{array}{l}\text { 1- All transpo } \\
\text { filters. } \\
\text { 2- Nutrient so } \\
\text { 3- Pre-chlorin } \\
\text { 4- Transport } e\end{array}$ & $\begin{array}{l}\text { experime } \\
\text { tion: } 1 \mathrm{mg} \\
\text { ion: } 2 \mathrm{mg} \\
\text { periments }\end{array}$ & $\begin{array}{l}\text { ncludi } \\
\begin{array}{l}-1 \\
-1\end{array} 0.1 \\
\text { aged } \\
\text { agre }\end{array}$ & $\begin{array}{l}\text { plicates) were cond } \\
\mathrm{L}^{-1}: 0.01 \mathrm{mg} \mathrm{P} \mathrm{L}^{-1} \\
\text { orine). } \\
\text { were all conducted }\end{array}$ & ed with different \\
\hline
\end{tabular}


Table 2. Water quality of influent water

\begin{tabular}{lll}
\hline Parameter & $\begin{array}{l}\text { Summer } \\
(\text { Mean } \pm \mathrm{SD})\end{array}$ & $\begin{array}{l}\text { Fall } \\
(\text { Mean } \pm \mathrm{SD})\end{array}$ \\
\hline $\mathrm{pH}$ & $8.4 \pm 0.1$ & $8.3 \pm 0.2$ \\
Alkalinity $\left(\mathrm{mg} \mathrm{CaCO}_{3} \mathrm{~L}^{-1}\right)$ & $87.0 \pm 1.6$ & $84.6 \pm 2.0$ \\
Conductivity $\left(\mu \mathrm{s} \mathrm{cm}^{-1}\right)$ & $303.2 \pm 4.8$ & $299.8 \pm 5.8$ \\
Total organic carbon $\left(\mathrm{mg} \mathrm{L}^{-1}\right)$ & $1.89 \pm 0.16$ & $2.46 \pm 0.26$ \\
Total hardness $\left(\mathrm{mg} \mathrm{CaCO}_{3} \mathrm{~L}^{-1}\right)$ & $117 \pm 1.0$ & $117 \pm 4.6$ \\
Calcium $\left(\mathrm{mg} \mathrm{L}^{-1}\right)$ & $32.9 \pm 0.3$ & $32.9 \pm 1.0$ \\
Magnesium $\left(\mathrm{mg} \mathrm{L}^{-1}\right)$ & $8.5 \pm 0.2$ & $8.5 \pm 0.7$ \\
\hline
\end{tabular}


Table 3. Mass balance of oocysts calculated with breakthrough curves and retention profiles (Fall)

\begin{tabular}{lcccccc}
\hline \multirow{2}{*}{ Media } & \multicolumn{3}{c}{ Mass balance } & \multicolumn{3}{c}{ Recovery $\left(\mathrm{R}^{1}\right)$} \\
\cline { 2 - 6 } & Effluent $^{2}$ & Filter bed $^{3}$ & Explained $^{4}$ & Influent & Effluent & Filter bed $^{5}$ \\
\hline New Sand & $97 \%$ & $17 \%$ & $113 \%$ & $98 \%$ & $87 \%$ & $512 \%$ \\
Aged Sand & $70 \%$ & $54 \%$ & $124 \%$ & $98 \%$ & $91 \%$ & $173 \%$ \\
Aged Sand $+\mathrm{Cl}_{2}$ & $83 \%$ & $19 \%$ & $102 \%$ & $94 \%$ & $83 \%$ & $118 \%$ \\
New Anthracite & $69 \%$ & $23 \%$ & $92 \%$ & $96 \%$ & $90 \%$ & $75 \%$ \\
Aged Anthracite & $72 \%$ & $15 \%$ & $87 \%$ & $96 \%$ & $83 \%$ & $54 \%$ \\
New GAC & $55 \%$ & $35 \%$ & $90 \%$ & $95 \%$ & $97 \%$ & $79 \%$ \\
Aged GAC & $29 \%$ & $25 \%$ & $55 \%$ & $96 \%$ & $84 \%$ & $36 \%$ \\
\hline
\end{tabular}

${ }^{1-} \mathrm{R}-$ Recovery of the enumeration method assessed with colorseeds ${ }^{\mathrm{TM}}$.

2- Calculated using Eq. (1) adjusted with $\mathrm{R}_{\text {influent }}$ and Eq. (2) adjusted with $\mathrm{R}_{\text {effluent. }}$

${ }^{3-}$ Calculated using Eq. (1) adjusted with $R_{\text {influent }}$ and Eq. (3).

${ }^{4-}$ Sum of $\%$ effluent and \% filter bed.

${ }^{5-}$ Calculated using Eq. (4). 
Table 4. Concentration of extracted metals per unit of volume of new and aged media

\begin{tabular}{|c|c|c|c|c|c|c|c|}
\hline \multirow{2}{*}{$\begin{array}{l}\text { Element } \\
\left(\mathrm{mg} \mathrm{cm}^{-3 *}\right) \\
(\text { mean } \pm \\
\text { SD) }\end{array}$} & \multicolumn{3}{|c|}{ Sand } & \multicolumn{2}{|c|}{ Anthracite } & \multicolumn{2}{|c|}{ GAC } \\
\hline & New & Aged & Aged $+\mathrm{Cl}_{2}$ & New & Aged & New & Aged \\
\hline $\mathrm{Al}$ & $0.08 \pm 0.01$ & $0.07 \pm 0.01$ & $0.09 \pm 0.02$ & $0.88 \pm 0.03$ & $1.02 \pm 0.12$ & $0.06 \pm 0.00$ & $0.16 \pm 0.05$ \\
\hline $\mathrm{Ca}$ & $0.35 \pm 0.13$ & $0.44 \pm 0.22$ & $0.40 \pm 0.07$ & $0.25 \pm 0.06$ & $0.36 \pm 0.04$ & $15.75 \pm 1.2$ & $18.1 \pm 0.67$ \\
\hline $\mathrm{Cu}$ & $0.01 \pm 0.00$ & $0.02 \pm 0.00$ & $0.03 \pm 0.00$ & $0.04 \pm 0.00$ & $0.12 \pm 0.00$ & $0.11 \pm 0.01$ & $0.69 \pm 0.28$ \\
\hline $\mathrm{Fe}$ & $0.81 \pm 0.52$ & $0.26 \pm 0.27$ & $0.29 \pm 0.17$ & $2.34 \pm 0.27$ & $2.71 \pm 0.11$ & $0.07 \pm 0.01$ & $0.12 \pm 0.02$ \\
\hline $\mathrm{Mg}$ & $0.18 \pm 0.06$ & $0.08 \pm 0.04$ & $0.05 \pm 0.03$ & $0.13 \pm 0.01$ & $0.18 \pm 0.01$ & $3.86 \pm 0.23$ & $3.26 \pm 0.40$ \\
\hline $\mathrm{Mn}$ & $\begin{array}{l}0.002 \pm \\
0.001\end{array}$ & $\begin{array}{l}0.001 \pm \\
0.001\end{array}$ & $\begin{array}{l}0.005 \pm \\
0.001\end{array}$ & $0.02 \pm 0.00$ & $0.01 \pm 0.00$ & $0.02 \pm 0.00$ & $0.01 \pm 0.01$ \\
\hline $\mathrm{Zn}$ & $\begin{array}{l}0.004 \pm \\
0.002\end{array}$ & $\begin{array}{l}0.003 \pm \\
0.000\end{array}$ & $\begin{array}{l}0.004 \pm \\
0.000\end{array}$ & $0.01 \pm 0.00$ & $0.02 \pm 0.00$ & $0.01 \pm 0.00$ & $0.09 \pm 0.04$ \\
\hline Sum & $1.43 \pm 0.37$ & $0.86 \pm 0.30$ & $0.87 \pm 0.21$ & $3.67 \pm 0.35$ & $4.42 \pm 0.26$ & $19.9 \pm 1.4$ & $22.5 \pm 0.72$ \\
\hline
\end{tabular}

*Using wet density 


\section{Figure Captions}

Fig. 1. Seasonal variability of Cryptosporidium removal (\%) by new media in summer (A) and fall (B).

Fig. 2. Comparison of Cryptosporidium removals (\%) by new and aged media in fall.

Fig. 3. Breakthrough curves of new media (open symbols), aged media (solid black symbols) and pre-chlorinated aged media (solid grey symbols) in sand (A), anthracite (B) and GAC (C) columns. Error bars represent minimum and maximum values.

Fig. 4. Measured retained oocyst concentration profiles of new media (open symbols), aged media (solid black symbols) and pre-chlorinated aged media (solid grey symbols) in sand $(\mathrm{A}, \mathrm{D})$, anthracite $(\mathrm{B}, \mathrm{E})$ and $\mathrm{GAC}(\mathrm{C}, \mathrm{F})$ columns corrected for the recovery of extraction protocols of every tested condition. Bold lines represent predictions based on classical CFT. Error bars represent minimum and maximum values.

Fig. 5. Measured polysaccharides (A) and proteins (B) on aged sand (circles), aged anthracite (triangles) and aged GAC (squares). Analyses were conducted in triplicate. Error bars represent the minimum and maximum values.

Fig. 6. Representative images of tested granular media. Comparison of SEM images of new sand (A), new anthracite (B) and new GAC (C). 
Fig. 7. Impact of media aging on the shape of GAC grains. Comparison of SEM images of new GAC (A) and aged GAC (B). 
Figure 1
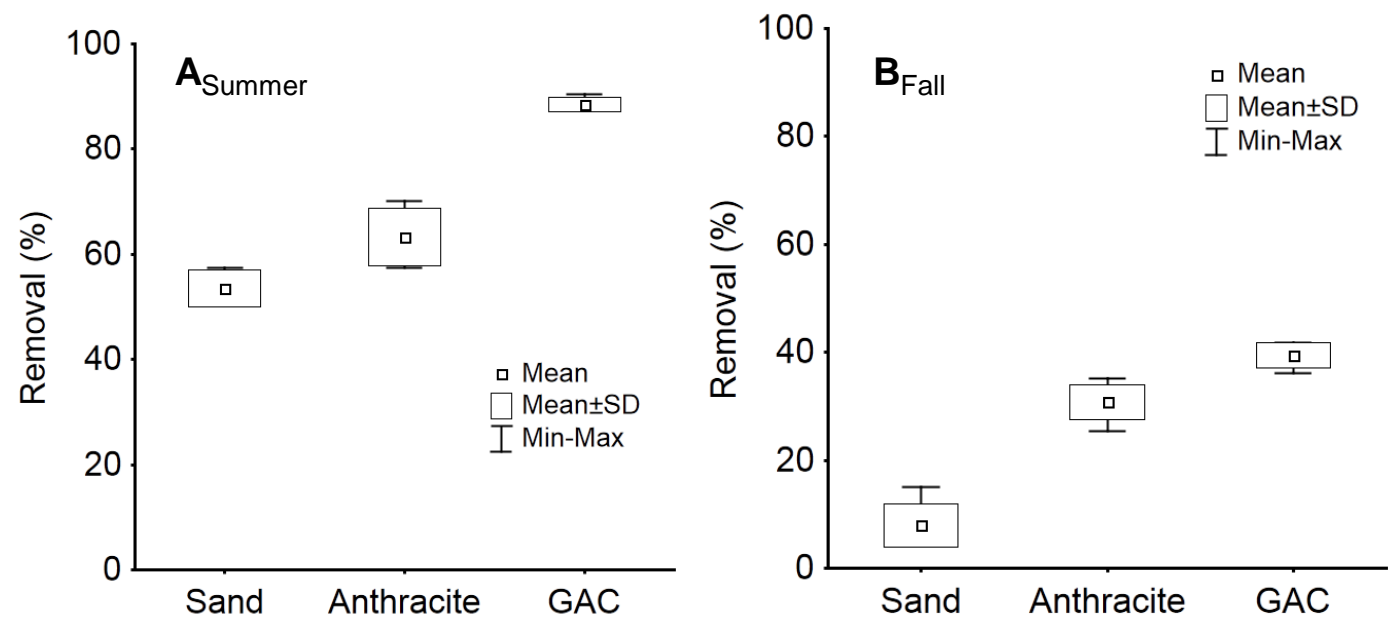
Figure 2

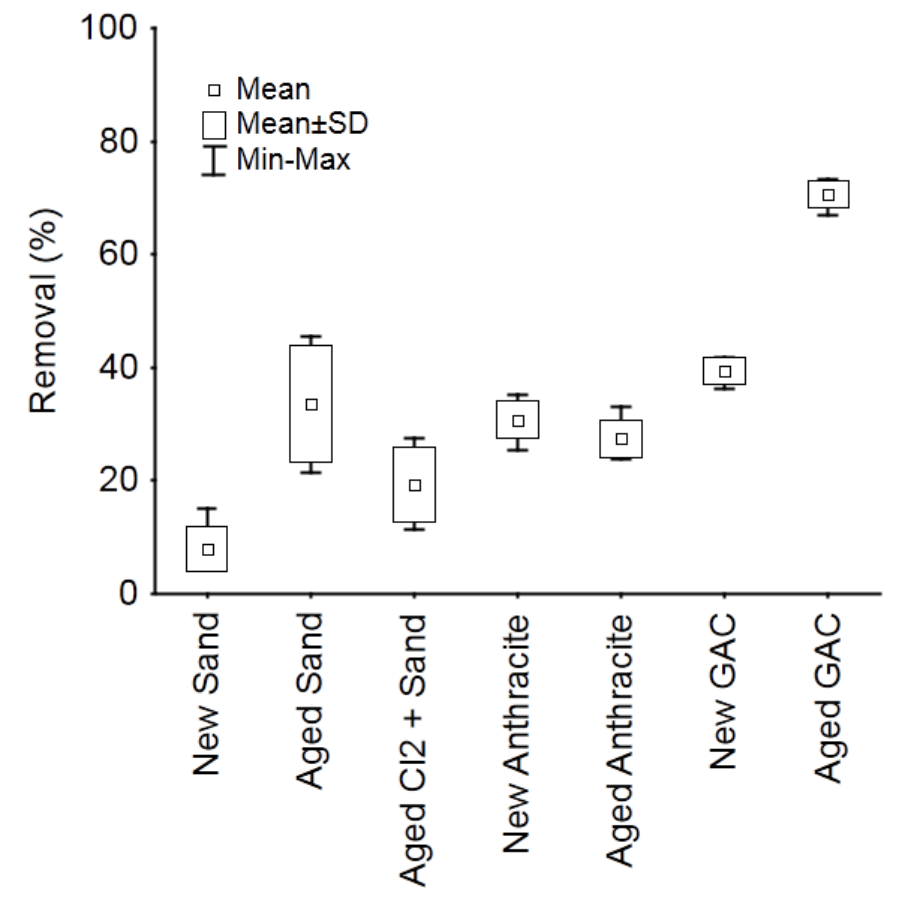


Figure 3
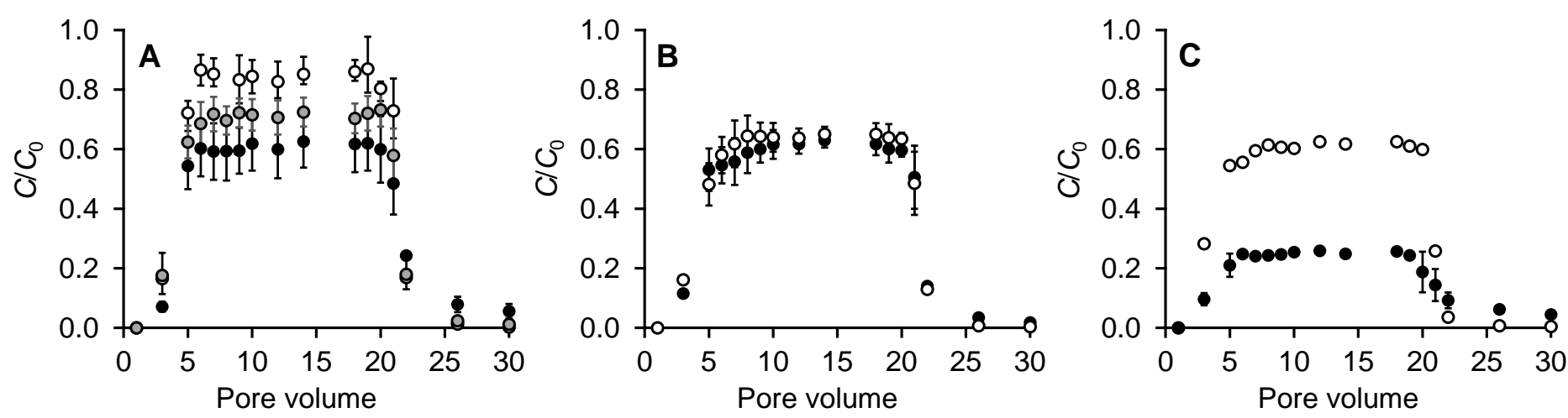


\section{Figure 4}
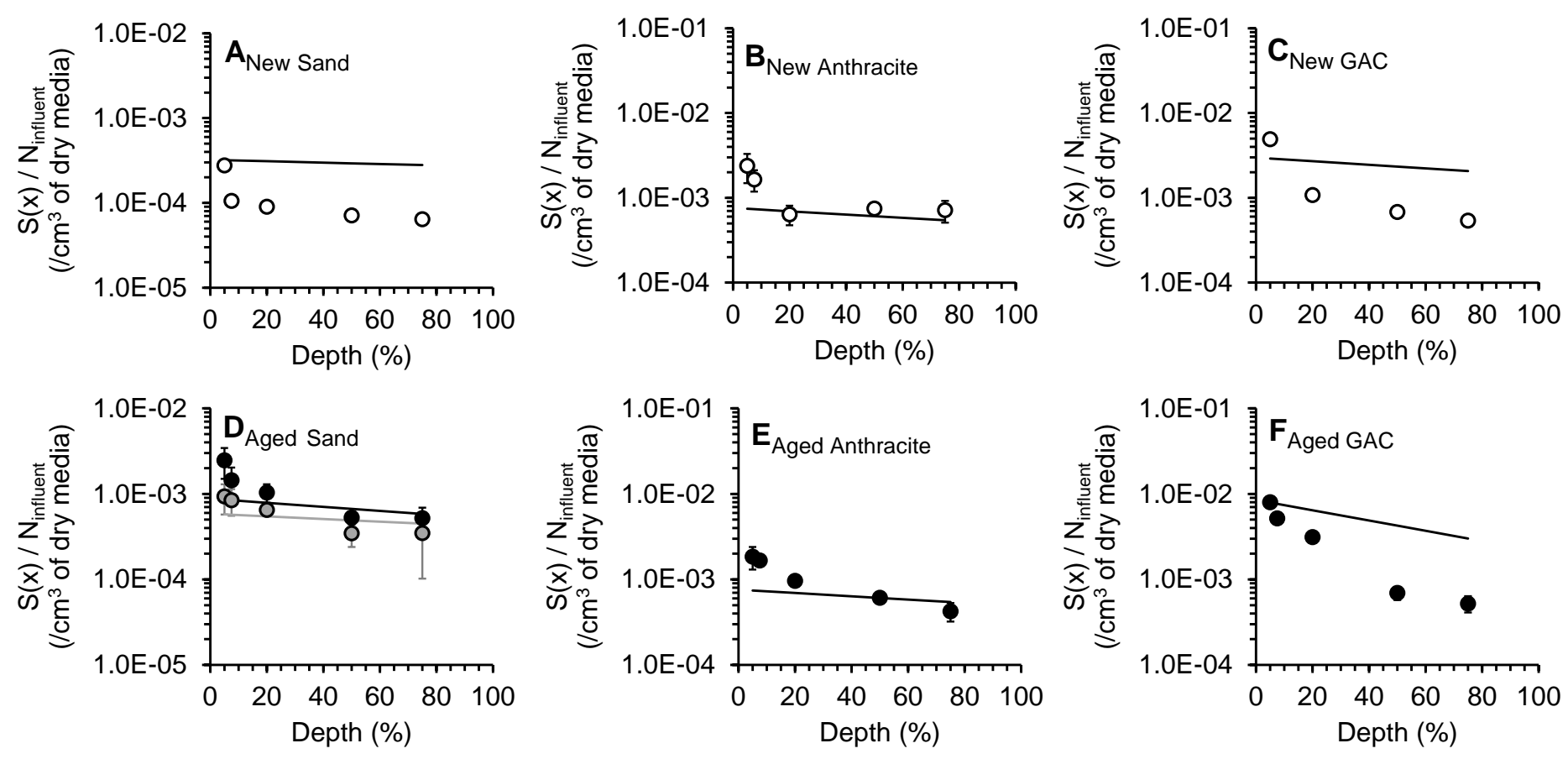
Figure 5
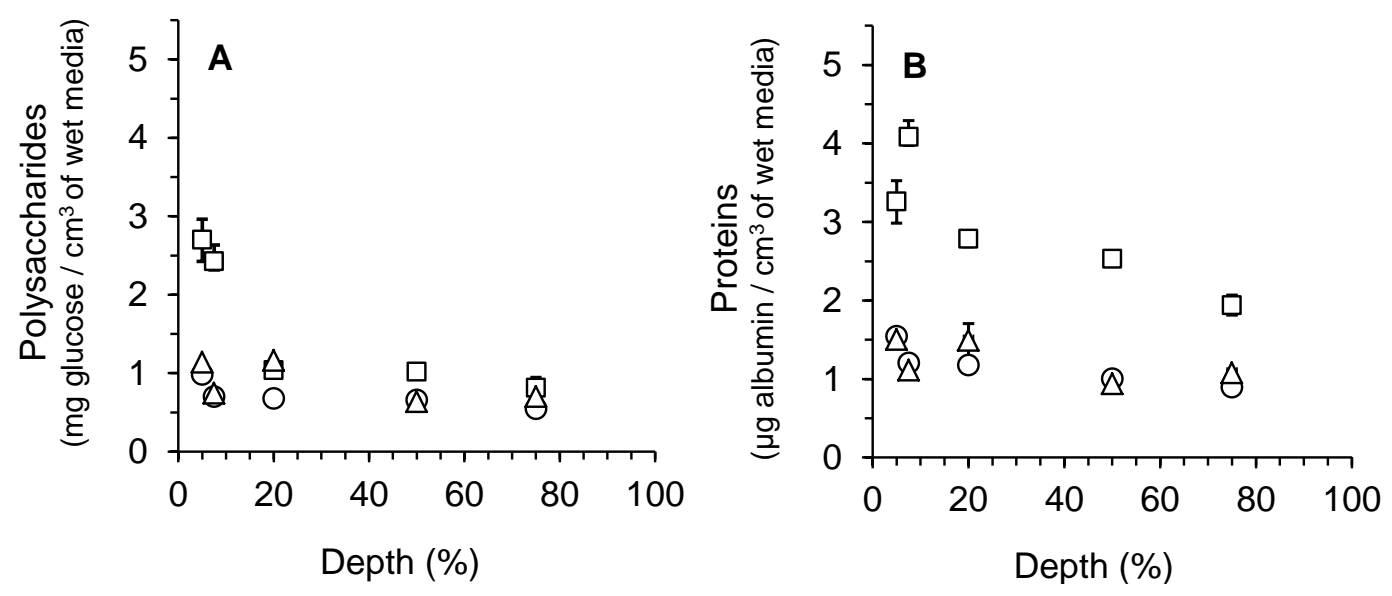
Figure 6
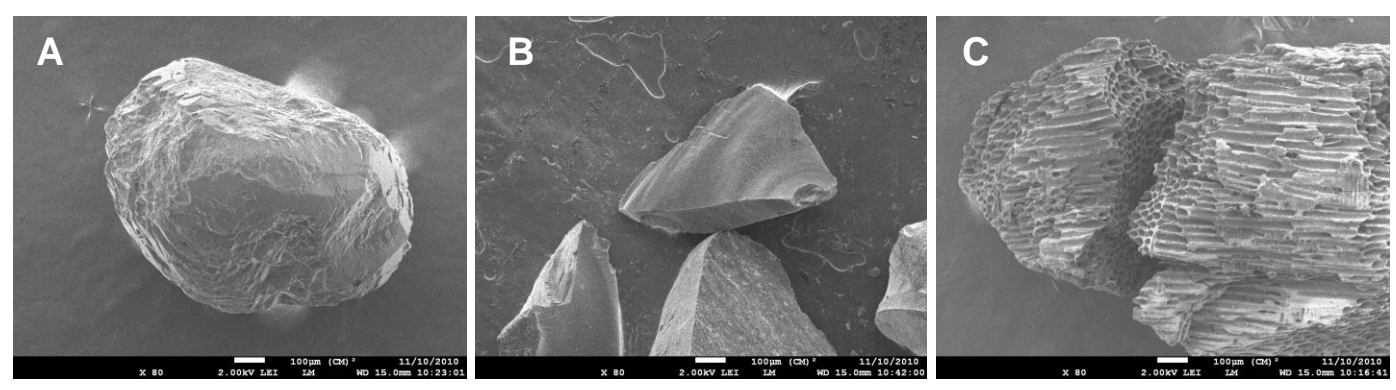
Figure 7
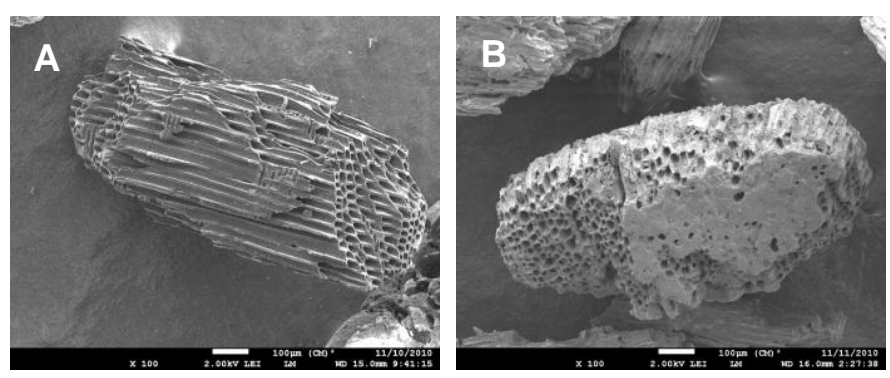


\section{Appendix}

\section{Characterization of grain size distribution}

Size distribution of grains as a function of depth
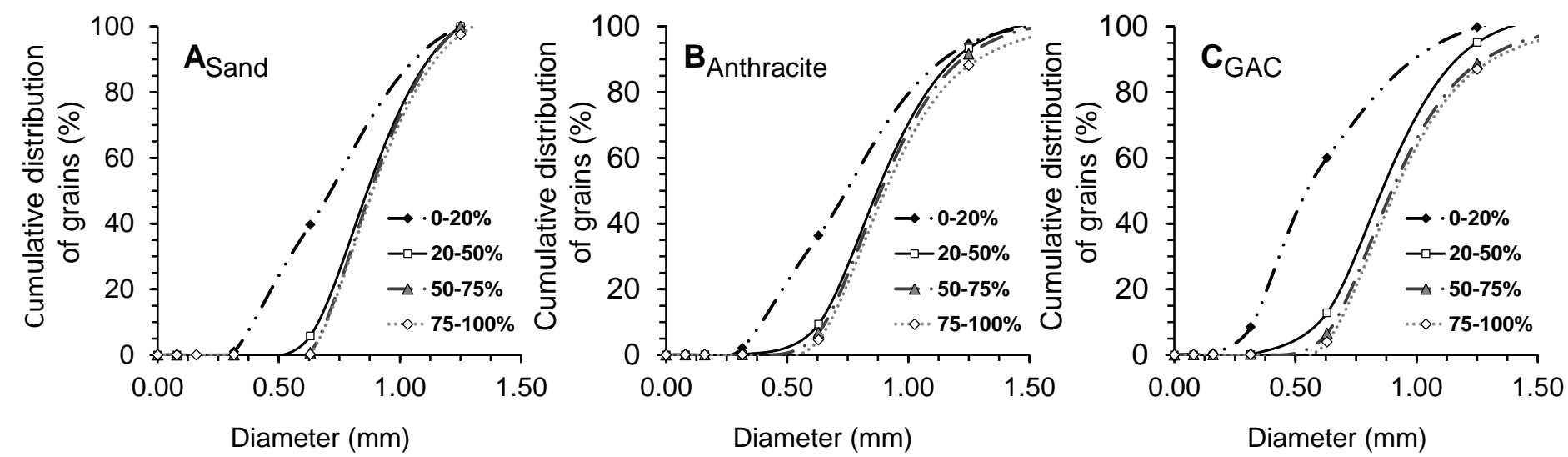

Fig. A1. Cumulative size distribution grains of new sand (A), new anthracite (B) and new GAC (C) as a function of depth subsequent to transport experiments. 
Characterization of the oocyst-to-collector grain size ratio with depth

Table A1. Grain diameter according to sieving experiments and oocyst-tocollector ratio as a function of depth of the filter bed

\begin{tabular}{llllll}
\hline \multirow{2}{*}{ Media } & \multirow{2}{*}{ Depth $(\%)$} & \multicolumn{2}{c}{ Diameter } & \multicolumn{2}{c}{$\mathrm{dp} / \mathrm{dc}^{1}$ ratio } \\
\cline { 3 - 6 } & & $d_{10}(\mathrm{~mm})$ & $d_{50}(\mathrm{~mm})$ & $d_{10}$ & $d_{50}$ \\
\hline Sand & $0-20$ & 0.40 & 0.75 & 0.0113 & 0.0060 \\
& $20-50$ & 0.66 & 0.86 & 0.0068 & 0.0052 \\
& $50-75$ & 0.69 & 0.88 & 0.0065 & 0.0051 \\
\multirow{5}{*}{ Anthracite } & $75-100$ & 0.70 & 0.89 & 0.0064 & 0.0051 \\
& $0-20$ & 0.40 & 0.75 & 0.0114 & 0.0060 \\
& $20-50$ & 0.64 & 0.87 & 0.0071 & 0.0052 \\
& $50-75$ & 0.66 & 0.89 & 0.0068 & 0.0051 \\
GAC & $75-100$ & 0.68 & 0.92 & 0.0066 & 0.0049 \\
& $0-20$ & 0.33 & 0.55 & 0.0136 & 0.0082 \\
& $20-50$ & 0.60 & 0.86 & 0.0075 & 0.0052 \\
& $50-75$ & 0.66 & 0.90 & 0.0068 & 0.0050 \\
& $75-100$ & 0.68 & 0.91 & 0.0066 & 0.0049 \\
\hline
\end{tabular}

${ }^{1-} d_{\mathrm{p}} / d_{\mathrm{c}}$ - ratio of oocyst diameter to the diameter of collector grains 
Predictions of the classical CFT model adjusted for the diameter of grains with column depth

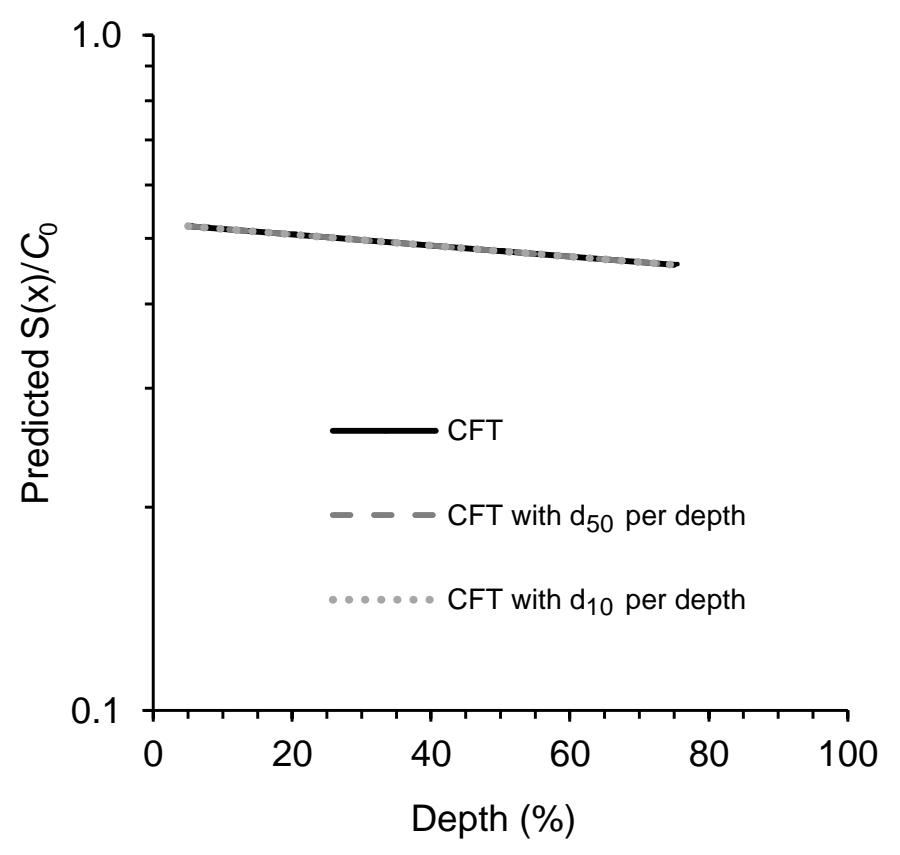

Fig. A2. Predicted oocyst retention profiles of new sand according to the classical CFT (bold line), predictions of classical CFT adjusted according to the median diameter $\left(\mathrm{d}_{50}\right)$ of collectors as a function of column depth as determined by sieving experiments (dashed line) and predictions of classical CFT adjusted according to the effective size $\left(\mathrm{d}_{10}\right)$ of collectors as a function of column depth as determined by sieving experiments (dotted line). 